\title{
Ear, nose, and throat in ANCA-associated vasculitis: a comprehensive review
}

\author{
Roberto Padoan ${ }^{1}$, Debora Campaniello', Mara Felicetti ${ }^{1}$, Diego Cazzador ${ }^{2,3}$, Franco Schiavon ${ }^{1}$ \\ 'Rheumatology Unit, Department of Medicine DIMED, University of Padova, Padova 35128, Italy. \\ ${ }^{2}$ Otorhinolaryngology Unit, Department of Neurosciences, University of Padova, Padova 35128, Italy. \\ ${ }^{3}$ Section of Human Anatomy, Department of Neurosciences, University of Padova, Padova 35128, Italy. \\ Correspondence to: Dr. Roberto Padoan, Rheumatology Unit, University of Padova, Via Giustiniani 2, Padova 35128, Italy. \\ E-mail: robertopadoan.reumatologia@gmail.com
}

How to cite this article: Padoan R, Campaniello D, Felicetti M, Cazzador D, Schiavon F. Ear, nose, and throat in ANCA-associated vasculitis: a comprehensive review. Vessel Plus 2021;5:41. https://dx.doi.org/10.20517/2574-1209.2021.41

Received: 28 Feb 2021 First Decision: 23 Apr 2021 Revised: 1 May 2021 Accepted: 21 May 2021 First online: 24 May 2021

Academic Editor: Luca Quartuccio Copy Editor: Yue-Yue Zhang Production Editor: Yue-Yue Zhang

\begin{abstract}
Ear, nose, and throat (ENT) involvement is a common feature in antineutrophil cytoplasmic antibody (ANCA)associated vasculitis (AAV), particularly in granulomatosis with polyangiitis and eosinophilic granulomatosis with polyangiitis. Over the last decade, substantial advancement has been made in understanding AAV pathogenesis, classification, and treatment. Typical ENT symptoms may include sinonasal, otologic, pharyngeal, and laryngeal manifestations. The otolaryngologic symptoms of AAV sometimes might be misdiagnosed in etiology as infectious or allergic. Thus, rapid recognition and early diagnosis of AAV as the cause of the symptoms prevent the risk of irreversible organ damage. The high impact of ENT symptoms on the quality of life of AAV patients confirms the importance of their early treatment through specific local and systemic approaches. Appropriate interdisciplinary management to early recognition of AAV and initiation of treatment may reduce morbidity in these patients. The purpose of this comprehensive review is to describe the clinical, histological, and radiological findings of ENT involvement in AAV and to update their surgical and therapeutic management, with a focus also on the role of a multidisciplinary team, involving the otorhinolaryngologist.
\end{abstract}

Keywords: Antineutrophil cytoplasmic antibody, ANCA-associated vasculitis, granulomatosis with polyangiitis, microscopic polyangiitis, eosinophilic granulomatosis with polyangiitis, ear, nose, throat 


\section{INTRODUCTION}

Antineutrophil cytoplasmic antibody (ANCA)-associated vasculitis (AAV) comprises a group of multisystem autoimmune disorders, characterized by inflammation of small - to medium-sized vessels, endothelial injury, and tissue damage. According to the 2012 revised Chapel Hill Consensus Conference nomenclature of vasculitides and the American College of Rheumatology (1990) classification criteria ${ }^{[1,2]}$, AAV are classified into three distinct disease phenotypes: granulomatosis with polyangiitis (GPA, formerly known as Wegener's granulomatosis), microscopic polyangiitis (MPA), and eosinophilic granulomatosis with polyangiitis (EGPA, Churg-Strauss syndrome).

Autoimmunity is documented by serum antibodies targeting cytoplasmic component of neutrophils, specifically proteinase 3 (PR3-ANCA) and myeloperoxidase (MPO-ANCA), due to loss of tolerance to neutrophil primary granule proteins ${ }^{[3]}$. ANCAs appear more closely associated with a vasculitic inflammation ${ }^{[4,5]}$, while granulomatous phenotype is predominantly linked to ANCA-negative serology and localized disease ${ }^{[6,7]}$.

Any organ or tissue may be involved in AAV, with clinical presentation ranging from severe organthreatening or life-threatening disease to less severe presentation or organ-limited manifestations ${ }^{[8]}$. GPA and MPA commonly affect the upper respiratory tract, lungs, and kidneys, often at the same time, while EGPA is characterized by asthma, hyper-eosinophilia, and heart and peripheral nervous system involvement ${ }^{[9]}$. However, EGPA is characterized by two different subsets, reflecting distinct underlying pathogeneses: a predominant "vasculitic phenotype" closely associated to ANCA and an "eosinophilic phenotype", which is interleukin-5 (IL-5) driven ${ }^{[10]}$.

Ear, nose, and throat (ENT) represent some of the most common sites of AAV manifestations, more often in GPA and EGPA, which generally precedes pulmonary or renal involvement. Although patients with ENT symptoms have better survival ${ }^{[7,11]}$ and less renal involvement ${ }^{[7,12]}$, they typically present a relapsing disease $^{[13]}$.

Typical ENT symptoms may include sinonasal, otologic, pharyngeal, and laryngeal manifestations [Figure 1]. Up to $95 \%$ of GPA patients show evidence of head and neck features and $85 \%$ have evidence of nasal or sinus problems ${ }^{[7,14]}$. In EGPA, head and neck manifestations could occur in $48 \%-96 \%$ of the cases at diagnosis ${ }^{[15,16]}$. Finally, involvement of head and neck organs in MPA is less common, being reported in $20 \%-30 \%$ of the patients ${ }^{[17]}$.

The otolaryngologic symptoms of GPA sometimes might be misdiagnosed in etiology as infectious or allergic. Thus, rapid recognition and early diagnosis of AAV as the cause of the symptoms prevent the risk of irreversible organ damage. Appropriate interdisciplinary management for early recognition of AAV and initiation of treatment may reduce morbidity in these patients.

The purpose of this comprehensive review is to describe the clinical, histological, and radiological features of ENT involvement in AAV and to update their surgical and therapeutic management, with a focus also on the role of a multidisciplinary team, involving the otorhinolaryngologist.

\section{SINONASAL MANIFESTATIONS}

The most frequently observed ENT manifestation of GPA is sinonasal involvement, being present in 60\%$85 \%$ of patients ${ }^{[7,18]}$. One of the first manifestations is nasal blockage, in association with hyposmia or anosmia when mucosal swelling occurs ${ }^{[19]}$. Purulent nasal drainage associated with the growth of 


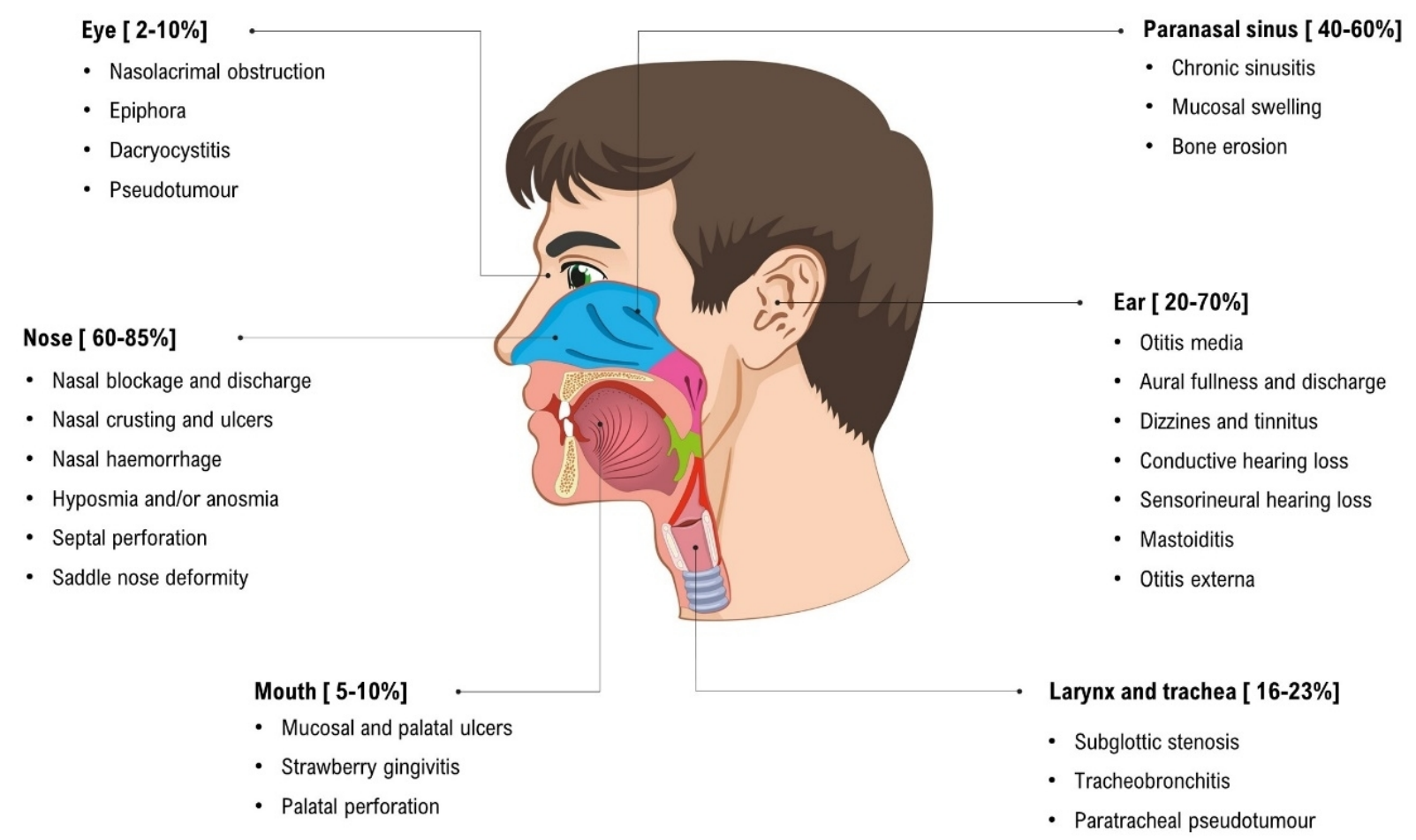

Figure 1. Ear, nose, and throat features in granulomatosis with polyangiitis according to the anatomical region and frequency of involvement.

Staphylococcus aureus or Pseudomonas aeruginosa can cause cacosmia. Epiphora may present as a sign of nasolacrimal duct and lacrimal sac involvement, as a result of granulomatous involvement, infection, or compression caused by mucosal inflammation ${ }^{[20]}$.

The nasal mucosa exhibits diffuse crusting, hemorrhage, and purulent discharge during active disease, resulting in nasal blockage, with symptoms reported by patients ranging from mild to very severe ${ }^{[19]}$ [Figure 2]. The most common site of disease activity is the anterior portion of the nasal septum, where all vessels of the septal cartilage converge and the septal perforation usually starts and extends over the entire cartilage ${ }^{[14]}$. Other structures of the nose, e.g., turbinates, might also be involved. At endoscopic examination, the nasal mucosa could appear granulating, with bloody submucosal patches or ulcerations, vulnerable, and covered with crusts ${ }^{[21]}$. In advanced stages, synechiae may also be observed. In the long term, inflammation and destruction of the nasal cartilage can lead to the typical saddle nose deformity ${ }^{[19]}$ [Figure 2].

The involvement of paranasal sinuses is also very common and could be detected by computed tomography (CT) or magnetic resonance imaging (MRI) ${ }^{[2]}$ [Figure 3]. However, during active disease, imaging is not capable of differentiate granulomatous inflammation from non-specific inflammation or infection ${ }^{[23]}$. The sinuses are likely to fill with scar tissue in the chronic stages of the disease, particularly after many relapses, and the maxillary sinuses also become narrower, with gradual ossification of the maxillary bone.

In MPA patients, involvement of the head and neck region is less common, but, when present, it resembles that of GPA. In a study conducted by Wojciechowska et al. ${ }^{[24]}$, comparing GPA and MPA patients, the most frequently reported manifestation in the ENT area in both groups was chronic rhinosinusitis, followed by 

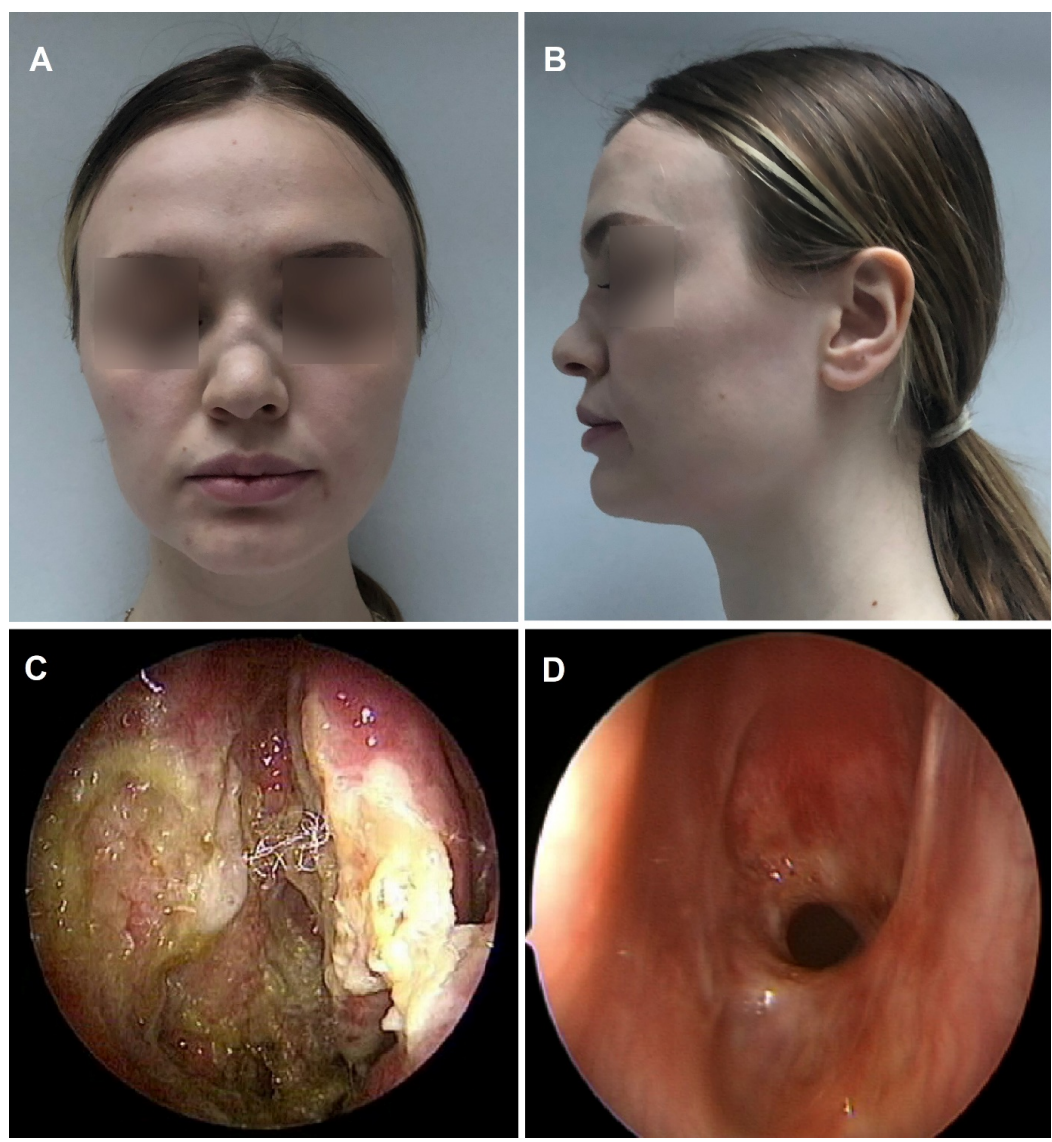

Figure 2. Clinical features of granulomatosis with polyangiitis manifestations in the ENT region. Frontal and sagittal view of saddle-nose deformity ( $A, B)$. Nasal endoscopy (C) showing subtotal septal perforation, bone erosion of the right middle and inferior turbinates, and diffuse crusting covering the nasal mucosa. Endoscopic view of a concentric subglottic stenosis (D).

epistaxis and purulent nasal discharge.

A significant proportion of EGPA patients suffer from ENT symptoms, usually manifesting as allergic rhinitis and chronic rhinosinusitis with or without polyps ${ }^{[25]}$. Olsen et al. ${ }^{[26]}$, in a series of 32 patients with EGPA, reported nasal disease in $69 \%$ of the cases, nasal polyps in $50 \%$, and nasal crusting in $36.3 \%$. They also found pansinusitis in $80 \%$ of patients. Another study on 28 EGPA patients ${ }^{[25]}$ demonstrated that ENT involvement was present in $75 \%$ of the cases, with allergic rhinitis and nasal polyposis as the most frequently observed manifestations at disease diagnosis, being observed in $42.8 \%$ and $76.1 \%$ of the patients, respectively. A history of chronic rhinosinusitis was present in $14.2 \%$ of the subjects. Chronic rhinosinusitis with diffuse and bilateral nasal polyps in EGPA is characterized by intense eosinophil tissue infiltration and a chronic-relapsing course in almost one-third of cases, despite surgery and medical treatment ${ }^{[27]}$. However, in EGPA nasal polyps, in addition to tissue eosinophil aggregates, a diffuse neutrophilic infiltration can be observed, supporting the hypothesis of neutrophils' entanglement in the inflammatory process, even in the absence of histological signs of vasculitis ${ }^{[2-30]}$. The role of neutrophil infiltrate in the nasal mucosa might be to amplify eosinophil tissue recruitment, in addition to contributing to inflammation ${ }^{[28]}$, and thus leading to a more refractory manifestation. 


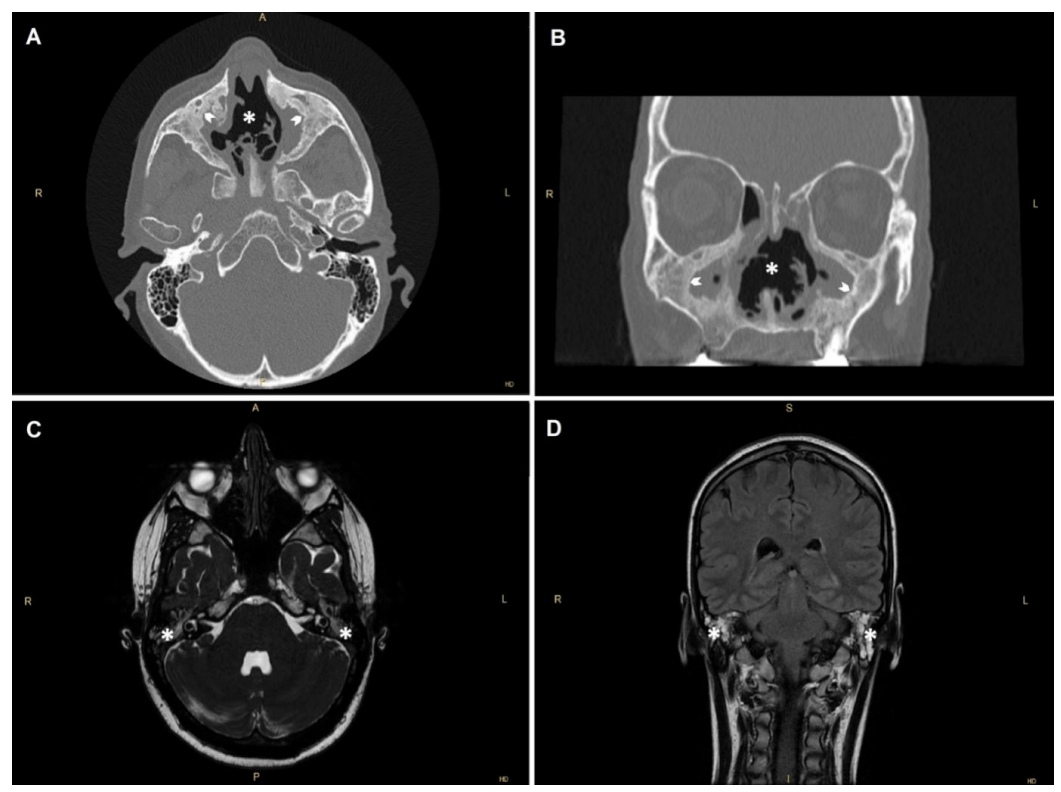

Figure 3. Radiological aspect of chronic rhinosinusitis, anterior septal perforation (asterisks), and maxillary sinus osteitis (arrowhead) in a patient diagnosed with granulomatosis with polyangiitis [CT scan, axial (A) and frontal (B) views]. T2-weighted MRI axial scan (C) and fluid attenuated inversion recovery (FLAIR) coronal scan (D) showing diffuse hyperintense opacification of the middle ear and mastoid cells in bilateral mastoiditis (asterisks).

\section{OTOLOGIC MANIFESTATIONS}

Otologic manifestations in systemic GPA are common, occurring in 20\%-70\% of the cases and representing the second most frequent symptoms of head and neck involvement ${ }^{[7,24,31]}$. The most involved site is the middle ear (23\%-70\%), leading frequently to hearing $\operatorname{loss}^{[21,32]}$, which could be the presenting symptom of GPA. The vast majority of patients have relapsing or refractory otitis media, which does not respond to regular treatment, such as antibiotics and insertion of tympanic vent tubes [Figure 3]. Other common symptoms are tinnitus, otalgia, aural fullness or discharge, and dizziness ${ }^{[21,33]}$. Hearing loss may be conductive, sensorineural, or mixed. Fluid or granulation in the middle ear induces conductive hearing loss, while the exact mechanisms of sensorineural hearing loss are not clear. It has been hypothesized that a vasculitic inflammation of the inner ear may be responsible for sensorineural deafness, although deposition of immune complexes in the cochlea or toxic effects of inflammatory byproducts passing through the membrane into the inner ear cannot be excluded ${ }^{[34]}$. The majority of patients are PR3-ANCA positive, although recently a high rate of ENT symptoms in MPO-ANCA-positive GPA patients was reported, which differs from the classic microscopic polyangiitis phenotype for presenting with a limited or milder disease and lower rate of renal involvement ${ }^{[35,36]}$.

Otoscopy examination can detect fluid in the middle ear and drum perforation. The audiometric pattern has been described as typically flat, although sometimes additional high frequency losses may coexist ${ }^{[37]}$. CT images of the temporal bone show soft tissue shadows and opacification in the middle ear and mastoid, while bone destruction may be observed in the tympanum and mastoid sinuses ${ }^{[2]}$.

Hearing loss and middle ear effusions are also the most common presenting otologic manifestations of EGPA. The typical manifestation is represented by a granulomatous otitis with chronic, thick discharge, which leads to a conductive hearing loss in patients with chronic paranasal abnormalities, eosinophilia, and asthma $^{[38,39]}$. 
Less commonly, localized AAV may presents only with otologic symptoms, without evidence of other AAV-related organ lesions. In these patients, not fulfilling the classification criteria for systemic vasculitis, the term OMAVV (otitis media with AAV) has been proposed ${ }^{[40,41]}$. Clinical criteria for OMAVV are reported in Table 1. Hearing loss represents the most common initial symptom, often associated with otorrhea, tinnitus, and vertigo or dizziness. Pachymeningitis or facial palsy may complicate the clinical course of OMAVV. An irreversible complete deafness despite treatment may develop in $3.5 \%-7.2 \%$ of patients ${ }^{[40]}$.

\section{TRACHEOBRONCHIAL MANIFESTATIONS}

Large airways involvement, in the form of tracheobronchial disease, is a less common GPA manifestation ${ }^{[42]}$. Subglottic stenosis (SGS) is the most frequent tracheobronchial stenosis type, with an estimated frequency of $16 \%-23 \%$ in adult patients with GPA, while it can be considered uncommon or even exceptional in $\mathrm{EGPA}^{[42-44]}$ [Figure 2]. It is one of the most common manifestations of ENT involvement in pediatric subjects ${ }^{[45]}$. SGS is defined as narrowing of the subglottic area within the cricoid cartilage ${ }^{[46]}$ that can lead to upper airway obstruction and potentially life-threatening consequences ${ }^{[47]}$. Involvement of the glottic and supraglottic larynx may less frequently occur, resulting in multilevel airway stenosis ${ }^{[48]}$. Stenosis may also extend into the distal trachea and bronchi ${ }^{[48]}$ including ulcerating tracheobronchitis with or without inflammatory pseudotumors ${ }^{[49]}$.

SGS patients are commonly female and younger (26-40 years) than patients with tracheobronchial stenosis $^{[45,47]}$.

The pathogenesis of subglottic stenosis in GPA remains unclear ${ }^{[50,51]}$, but the association of a vasculitic process in the setting of active inflammation due to laryngopharyngeal reflux ${ }^{[4,52]}$ and mechanical forces related to turbulent subglottic airflow ${ }^{[53]}$ may synergistically produce a hyperactive healing response that leads to cartilaginous fibrotic scarring and stenosis ${ }^{[50]}$.

Subglottic stenosis likely increases gradually, allowing the patient to adjust his breathing pattern until a critical stenosis is reached. Typically, patients remain mild symptomatic or asymptomatic until about $75 \%$ of airway stenosis ( $60 \%$ in children) is reached ${ }^{[50]}$. Some patients report "asthmatic-like" symptoms for many years before diagnosis ${ }^{[43]}$. Patients with SGS may develop symptoms gradually, from non-specific cough, hoarseness, shortness of breath, pharyngodynia, hemoptysis, or vocal changes, finally to stridor or dyspnea on exertion when a critical point of stenosis is reached ${ }^{[18,54,55]}$. As the airway caliber narrows, obstruction may result from crusts, mucous plug, and thick secretions caused by inflammation of the mucosa or infections, as well as the subglottic lesion itself ${ }^{[50,56]}$. Unilateral or bilateral vocal cord fixation can be a consequence of cricoarytenoid joint involvement ${ }^{[57]}$. Occasionally, patients presenting with acute obstruction require emergency tracheostomy ${ }^{[18]}$. Recognition of active tracheobronchial or SGS in GPA can be challenging because SGS seems to progress irrespective of systemic GPA disease activity ${ }^{[3,53]}$. It may present as the first symptom or as a late manifestation of the disease ${ }^{[48]}$. Patients with subglottic inflammation are more likely to be ANCA negative ${ }^{[47]}$ and to have endobronchial disease, ENT manifestations (destructive sinonasal disease as well), pulmonary manifestations, and constitutional symptoms ${ }^{[47]}$, and they less frequently have nervous system and renal involvement ${ }^{[49]}$. The presence of SGS must be urgently investigated in patients with GPA who develop respiratory symptoms, even in the absence of another disease flare ${ }^{[47,50]}$.

Even though SGS in GPA is a serious and potentially life-threatening complication, no standardized diagnostic and therapeutic approach exists. It is still debated which diagnostic methods should be recommended (serial bronchoscopies, lung function tests, and virtual endoscopy) for diagnosis and follow- 
Table 1. Diagnostic criteria of otitis media with anti-neutrophil cytoplasmic antibody (ANCA)-associated vasculitis (OMAAV)

Diagnostic criteria of OMAAV

OMAVV is diagnosed if the following three criteria $(A, B, C)$ are fulfilled

(A) At least one of the following clinical courses:

Intractable otitis media with effusion or granulation, which is resistant to antibiotics and insertion of tympanostomy tube Progressive deterioration of bone conduction hearing levels

(B) At least one of the following features:

Already diagnosed as AAV (GPA; MPA; EGPA) based on the involvement of others organs

Positivity for serum MPO-or PR3-ANCA

- Histopathology consistent with AAV i.e., necrotizing vasculitis predominantly affecting small vessels with or without granulomatous extravascular inflammation

At least one of the following accompanying sig/symptoms of AAV-related involvement:

a. Involvements with upper airway tracts other than ear, scleritis lung and/or kidney

b. Facial palsy

c. Hypertrophic pachimeningytis

d. Multiple mononeuropathy

e. Transient alleviation of symptoms/sign with administration of $0.5-1 \mathrm{mg} / \mathrm{Kg}$ prednisolone and relapse with discontinuation of treatment

(C) Differential diagnosis:

- Cholesteatoma, cholesterol granuloma, eosinophilic otitis media, tuberculosis, otitis externa, skull base osteomyelitis, neoplasms (malignancy, inflammatory myofibroblastic tumor, etc.) otitis media or inner ear inflammation caused by autoimmune diseases and vasculitis other than AAV

ANCA: Anti-neutrophil cytoplasmic antibodies; AAV: ANCA-associated vasculitis; EGPA: eosinophilic granulomatosis with polyangiitis; GPA: granulomatosis with polyangiitis; MPA: microscopic polyangiits. MPO: myeloperoxidase; PR3: proteinase 3.

$\mathrm{up}^{[54]}$.

Laryngeal endoscopy, using a flexible laryngoscope, should be performed as part of routine initial evaluation. Endoscopy typically reveals a circumferential narrowing associated with friable, erythematous mucosa or a inelastic fibrotic thickening, depending on the inflammatory state of the stenosis ${ }^{[18]}$ but without specific findings for vasculitis ${ }^{[53]}$. Biopsy of the SGS should be performed cautiously because it can lead to exacerbation of the stenosis secondary to edema and progression of the scarring ${ }^{[58]}$. Among imaging techniques, MRI has a sensitivity of $87.5 \%$ and a specificity of $60 \%$ in recognizing inflammatory activity in SGS. It can detect circumscribed intramural granulomatous lesions or discriminate between regional and circumferential wall thickening ${ }^{[43]}$. Because $15 \%-55 \%$ of GPA patients have additional bronchial stenotic segments, spiral CT with three-dimensional reconstruction of the laryngotracheal lumen is useful to allow the assessment of the entire tracheobronchial pathway ${ }^{[50]}$.

Dynamic expiratory CT has been proposed as a screening method to assess tracheal stenosis, being able to evaluate dynamic pathological changes during respiration in addition to detecting fixed stenoses ${ }^{[47]}$.

Most cases of non-vasculitic subglottic stenosis are secondary to post-intubation scarring or laryngotracheal trauma ${ }^{[43]}$. Differential diagnosis should also include neoplastic and infectious factors ${ }^{[51]}$. It is important to distinguish these patients from congenital or idiopathic SGS ${ }^{[48]}$. Subglottic laryngotracheal stenosis has been reported in other forms of vasculitis such as relapsing polychondritis ${ }^{[46]}$.

\section{ORAL MANIFESTATIONS}

Oral lesions in GPA could be observed at disease onset in around 2\% of cases and could appear in about 5\%$10 \%$ of patients during disease course ${ }^{[14]}$. These manifestations can be characterized by rapidly evolving ulceration, necrosis with neutrophil-rich infiltrates, or chronic granulomatous localized process slowly leading to mucosal and bone destruction ${ }^{[59]}$. Oral lesions include mucosal palatal and lingual ulcerations, aphthae, and non-healing extraction sockets ${ }^{[5,60]}$. Finally, specific gingival lesions, known as "strawberry gingivitis", can be observed, and they are characterized by exophytic gingival swelling of reddish purple 
color with petechial hemorrhages that resemble strawberries ${ }^{[1-64]}$. The differential diagnosis of mucosal ulcers should include sarcoidosis, Crohn's disease, infections (mycobacterial, leishmaniasis, and paracoccidioidomycosis), and drug abuse ${ }^{[14]}$. Finally, in GPA and other granulomatous infectious diseases, palatal perforation is exceedingly unusual ${ }^{[65]}$.

\section{TUMOR-LIKE MANIFESTATIONS}

Atypical lesions are often the presenting feature in GPA, including mass lesion. This manifestation may present as parapharyngeal mass, parotid mass, sinonasal and maxillary sinus lesions, and subglottic paratracheal mass ${ }^{[6-69]}$. Typically, masses are associated with PR3-ANCA and occur at early stage of the disease, usually as part of a systemic disease (lung and kidney). Pseudotumor in the ENT region may present with secondary cranial neuropathies. Nerve palsy may occur as single or multiple cranial nerve involvement. Evolution to osteomyelitis by invasive mass is possible ${ }^{[70]}$. Parapharyngeal involvement is reported by description of a parapharyngeal mass or secondary to local extension from contiguous parotid mass.

Tumor-like lesions in the ENT region are associated with a higher rate of partial response or refractory disease. Furthermore, surgical procedures can be difficult in this region.

\section{HISTOLOGICAL FINDINGS}

As the nose and paranasal sinuses are frequently involved in AAV and easily accessible, an intranasal biopsy is believed to be the one of the best ways to achieve histological confirmation. Thus, diagnostic biopsies of the nasal mucosa can be performed under local anesthesia, being relatively minimally invasive; however, the maxillary and ethmoid sinuses are also alternative regions for representative biopsies ${ }^{[14]}$.

However, biopsy specimens from the ENT region are often small, making it therefore difficult to achieve a conclusive histological diagnosis of AAV. It is recommended to take multiple large biopsies $(>5 \mathrm{~mm})$ from the edge of the inflamed area, in order to maximize the chance of obtaining a diagnostic biopsy ${ }^{[71]}$. It is rare to see at the same time all the typical features, including necrotizing granulomata with giant cells and neutrophil-predominant vasculitis ${ }^{[72]}$. Indeed, non-specific features, such as acute or chronic inflammation, are usually found in most head and neck biopsy specimens, which does not help in confirming the diagnosis of $\mathrm{AAV}^{[73]}$. Only in up to $16 \%$ of GPA cases can the classic triad of vasculitis, necrosis, and granulomatous inflammation be seen, while vasculitis and granulomas are found $21 \%$ of cases and vasculitic and necrosis in $23 \%$ of specimens ${ }^{[7]}$. However, when the clinical picture fits the diagnosis of AAV despite a negative histopathological result, a high index of suspicion must be preserved.

Although intranasal biopsies are the most common way to validate a diagnosis in GPA and EGPA, intranasal biopsies from MPA patients seldom reveal the existence of vasculitis and therefore are of limited value $^{[73]}$.

It is not recommended to perform biopsy of middle ear or mastoid region, given the technical difficulty of obtaining an appropriate biopsy specimen and the high rate of inconclusive histological finding ${ }^{[74]}$.

In EGPA patients, during the prodromal phase, it is extremely difficult to clearly distinguish chronic rhinosinusitis from inflammation due to vasculitis. Histologically, nasal specimens usually show diffuse eosinophilic tissue infiltration ${ }^{[75]}$, as in eosinophilic-type nasal polyposis, while only less than $10 \%$ of specimens reveal necrotizing vasculitis or eosinophilic granuloma. The diagnostic yield can be increased up to $50 \%$ if histological examination is performed on deep biopsy or surgical specimens of sinus tissue 
obtained under general anesthesia ${ }^{[76]}$. Recent data demonstrate that, alongside the well-known eosinophilrich inflammation, there may be other cells contributing to the inflammatory process, such as neutrophils ${ }^{[28]}$, but specific markers are still lacking.

\section{RADIOLOGICAL FINDINGS}

Performing CT or MRI scans may be used and recommended on an individual basis, according to the location of the involvement and the clinical manifestations.

In a systematic review ${ }^{[77]}$ carried out on sinus imaging findings in GPA, 92.6\% of the patients had abnormalities on sinus CT: mucosal thickening of the paranasal sinuses and nasal fossae ( $87.7 \%)$, bony destruction (59.9\%), and osteoneogenesis with foci of sclerosing osteitis and bone thickening (46\%-59\%) [Figure 3]. Bony obliteration of sinuses is relatively rare. Septal erosion was observed in $59.4 \%$ of the patients and $27.1 \%$ had orbital involvement. MRI imaging showed similar rates of mucosal thickening (89.9\%) and granulomas in $14.5 \%$ of the patients, while conversely bony erosion was reported in only $10.1 \%$ of the cases. In EGPA patients, mucosal thickening, nasal polyps, and pansinusitis are commonly reported, while bony destruction is absent ${ }^{[78]}$. An alternative diagnosis, rather than AAV, should be suspected in the presence of bone erosion of the hard palate or the maxillary wall and alveolus. However, even though CT or MRI features are often non-specific, imaging might improve management of AAV patients, for example by quantifying the extent of sinus involvement.

Finally, CT and MRI scans can also be used to better define lesions in subglottic/tracheal stenosis. These tests are also suggested for patients with ear involvement who are refractory to treatment or in cases of cranial nerve palsy ${ }^{[7]}$.

\section{DIFFERENTIAL DIAGNOSIS}

Many of the clinical features of AAV are non-specific, and, thus, the potential differential diagnoses are several. In the presence of ulcerative lesions of the ENT region, AAV should be included in the differential diagnosis; in addition, infections, inflammatory autoimmune diseases, malignancies, and substance abuse conditions can also cause granulomatous inflammation, which may lead to extensive damage [Table 2]. Complete and careful examination is warranted, as well as looking for evidence of different organ involvement other than the head and neck region. Moreover, all patients presenting with ENT symptoms resembling GPA should be evaluated with flexible endoscopy and imaging (CT and/or MRI) in order to quantify disease extent and identify the best area to biopsy. Additionally, serologic assessment should be performed; firstly, ANCA testing can lead to the proper diagnosis. An increasing presence of clinical, serological, and histological factors should enforce clinical suspicion of AAV, if there are no signs or symptoms that lead to a different diagnosis.

\section{TREATMENT OPTIONS}

\section{Local treatment}

Tissue damage caused by inflammation represents one of the major sources of morbidity for patients with AAV and ENT involvement. Some of these symptoms need adequate treatments, administered alone or in combination with systemic medical treatment, such as surgical or endoscopic repair or the delivery of topical or injectable medications directly to the site of disease ${ }^{[80]}$.

Sinonasal symptoms can be relieved with vigorous nasal irrigation and topical medications applied directly to the nasal mucosa. This can be achieved in combination with glucocorticoids. Nasal irrigation with saline on a regular basis can help to dissolve crusts that can become a pablum for bacterial proliferation and block 
Table 2. Differential diagnoses of ear, nose and throat inflammatory, granulomatous and necrotizing lesions

\begin{tabular}{|c|c|c|c|}
\hline Infections & $\begin{array}{l}\text { Inflammatory autoimmune } \\
\text { diseases }\end{array}$ & Malignancies & Substances \\
\hline $\begin{array}{l}\text { Bacterial } \\
\text { Tuberculosis } \\
\text { Leprosy } \\
\text { Syphilis } \\
\text { Rhinoscleroma } \\
\text { Actinomicosis }\end{array}$ & $\begin{array}{l}\text { ANCA-associated vasculitis } \\
\text { 1. Granulomatosis with polyangiits } \\
\text { 2. Eosinophilic granulomatosis with } \\
\text { polyangiits } \\
\text { 3. Microscopic polyangiits }\end{array}$ & $\begin{array}{l}\text { Nasal NK-T-cell lymphoma (midline } \\
\text { lethal granuloma) }\end{array}$ & $\begin{array}{l}\text { Cocaine-induced midline destructive } \\
\text { lesions (CIMDL) }\end{array}$ \\
\hline $\begin{array}{l}\text { Fungal } \\
\text { Zygomycosis } \\
\text { Dermatacietes } \\
\text { Rhinosporidiosis } \\
\text { Blastomycosis } \\
\text { Histoplasmosis } \\
\text { Sporotrichosis } \\
\text { Coccidioidomycosis }\end{array}$ & $\begin{array}{l}\text { Other autoimmune diseases } \\
\text { 1. IgG4-related disease } \\
\text { 2. Sarcoidosis } \\
\text { 3. Rheumatoid arthritis } \\
\text { 4. Relapsing polychondritis } \\
\text { 5. Systemic lupus erythematosus }\end{array}$ & & Levamisole-induced Vasculitis (LIV) \\
\hline $\begin{array}{l}\text { Protozoal } \\
\text { Leishmaniasis }\end{array}$ & & & Propylthiouracil-induced vascultis \\
\hline
\end{tabular}

nasal passages. Nasal lubricants applied directly to the mucosa or emollients added to nasal saline washes can help reduce dried nasal mucus and soften crusts, making them easily removable ${ }^{[81]}$. Topical application of antibiotics may be useful to eradicate Staphylococcus aureus from the nose.

\section{Systemic treatment}

The combination of corticosteroids and immunosuppressants is the mainstay of AAV treatment. Among immunosuppressive agents, cyclophosphamide is the conventional induction treatment for systemic or diffuse GPA ${ }^{[82]}$, while methotrexate is an alternative for forms of GPA that are not life-threatening ${ }^{[83]}$. Induction treatment allows remission to be achieved in more than $80 \%$ of cases. For maintenance treatment, azathioprine is the most widely used ${ }^{[84]}$. In localized disease, in addition to methotrexate and trimethoprim, sulfamethoxazole also appears to be effective, with a reduction in the relapse rate, mainly in ENT, possibly for action against Staphylococcus aureus ${ }^{[85]}$.

Rituximab (RTX), a chimeric human-mouse monoclonal antibody against CD20, is nowadays approved and widely used in the treatment of $\mathrm{AAV}^{[82]}$, with a good safety profile ${ }^{[86]}$. RTX can be used in combination with corticosteroids as a first-line treatment for severe AAVs, particularly when cyclophosphamide is not recommended ${ }^{[87]}$.

Regarding ENT manifestations, RTX is not usually recommended in patients without life- or organthreatening manifestations ${ }^{[82]}$. However, RTX as rescue therapy has been administered in GPA with refractory ENT manifestations. A recent case series reported a good response of refractory OMAAV after RTX treatment ${ }^{[88]}$.

In a large retrospective cohort of $59 \mathrm{AAV}$ patients with orbital masses, RTX resulted highly effective (remission rate: RTX 91\% vs. cyclophosphamide 52\%). However, in this study, all patients received glucocorticoids without a standardized protocol, RTX was administered only in 19\% of the patients, and there was no subgroup analysis between patients treated with RTX and patients treated with other immunosuppressive agents to assess if other features/treatments could have influenced the outcome ${ }^{[89]}$. In a previous case series of refractory GPA treated with RTX, Holle et al. ${ }^{[00]}$ reported a much lower remission/improvement rate in patients with orbital masses (44.4\%). Nevertheless, it is important to stress that the retroorbital disease is not recommended to be treated with a mild immunosuppressive regimen (e.g., methotrexate or mycophenolate) ${ }^{[82]}$. 
RTX was reported to be effective in the management of tracheobronchial stenosis (SGS and bronchial stenosis). Girard et al.$^{[42]}$ reported a remission rate in $80 \%$ in GPA patients with tracheobronchial stenosis when treated with RTX. However, the remission rate was lower with SGS (67\%) and in patients requiring local treatment $(67 \%)^{[42]}$.

Other SGS case reports treated with RTX have been published, in addition to the French case series. Most reported a good outcome even in pediatric cases, but there are reports of no response. Moreover, most patients received glucocorticoids and were also locally or surgically treated, so the real effect of RTX alone is difficult to assess ${ }^{[91-93]}$.

Despite aggressive immunosuppressant treatment, SGS seems to respond less than other GPA manifestations and to be burdened with a high risk of relapse. In these cases, the patients could require a surgical treatment, so an expert laryngologist is crucial in the patient's monitoring and management ${ }^{[49]}$.

For EGPA management, treatment is usually borrowed from the GPA/MPA experience, because EGPA is frequently excluded from AAV randomized clinical trials, and, when included, EGPA patients are only a minority. Moreover, very few clinical trials are specifically designed for EGPA and only one considered a monoclonal antibody $(\mathrm{mAb})^{[94-96]}$

Upper and lower airway involvement management in EGPA is challenging because ENT and asthma exacerbations are an expression of non-severe disease but very common and dependent on glucocorticoids (up to $84 \%$ of patients) ${ }^{[97]}$.

In the last years, new treatments have been proposed for these manifestations; however, more evidence is focused on refractory and glucocorticoid-dependent asthma than ENT manifestations such as chronic rhinitis and nasal polyposis.

The pathogenesis of EGPA is still not fully clarified, but a direct pathogenic effect of eosinophil infiltration into different tissues has been demonstrated. Eosinophils are strongly activated and regulated by IL-5, which is primary produced by Th2 cells ${ }^{[98]}$.

Recently, a phase 3 randomized controlled trial including relapsing, refractory, or glucocorticoid-dependent EGPA, the MIRRA trial, was published. This trial demonstrates that mepolizumab, an anti-IL-5 mAb, significantly reduced the frequency of disease relapses, including asthma and sinonasal relapses, and allowed the tapering or reduction of glucocorticoids ${ }^{[94]}$.

Regarding mepolizumab, a large observational respective study confirmed the efficacy of this drug for EGPA patients with severe glucocorticoid-dependent asthma. The study included patients treated with mepolizumab (100 mg monthly, compared to the $300 \mathrm{mg}$ monthly dosage administered in the MIRRA trial). Canzian et al ${ }^{[99]}$ reported some benefit even with the low dosage that could be acceptable as first-line therapy, but they highlighted that it has not been compared to the validated dosage of $300 \mathrm{mg}$ monthly.

Since the results of the MIRRA trial were published, other anti-IL-5 medications have been considered promising in EGPA. Reslizumab, for example, has been investigated in an open label pilot study in EGPA with apparent favorable outcome on disease exacerbations ${ }^{[100]}$. Similarly, a prospective open label pilot study on benralizumab, an anti-IL-5 receptor mAb, was recently published considering a few EGPA patients, which reported a good glucocorticoid sparing effect and improvement of EGPA exacerbations, including 
airway symptoms ${ }^{[101]}$. Interestingly, a recent case series reported a good steroid sparing effect of benralizumab on EGPA asthma, even in patients with no or poor response to mepolizumab. Moreover, in this study, the authors reported a significant improvement of patients' reported outcomes on ENT symptoms ${ }^{[102]}$.

Up to now, it has been widely demonstrated that the systemic increase of IL-5 is crucial for promoting eosinophilia; however, IL-5 increase is not always sufficient to cause eosinophil-mediated tissue damage or pathological condition ${ }^{[98]}$. In specific tissues, local inflammatory environment and tissue-specific IL-5 concurrently contribute to full eosinophil activation ${ }^{[103]}$. In situ activation and differentiation of eosinophils might be associated with eosinophil heterogeneity and thus inconsistent response to treatment, according to specific organs. Although significant differences in efficacy of anti-IL-5 treatments have not been demonstrated, benralizumab extensively depleted eosinophils via antibody-dependent cell-mediated cytotoxicity, compared with that of mepolizumab ${ }^{[104]}$. However, despite deep depletion of eosinophils, a post-hoc analysis of the randomized controlled trial did not show significant differences between mepolizumab and benralizumab ${ }^{[105]}$. The reason for the discrepancy between the eosinophil depletion and clinical improvement is still unclear.

Another interesting drug is omalizumab, an anti-human immunoglobulin E murine $\mathrm{mAb}$, which was demonstrated to be effective against allergic asthma, refractory chronic rhinosinusitis with nasal polyps, and refractory chronic spontaneous urticaria ${ }^{[106-108]}$. Some authors reported a favorable experience with omalizumab as steroid sparing agent in EGPA with persistent asthma and ENT manifestations, but half of the patients suffered asthma exacerbations ${ }^{[109-112]}$.

However, there is also evidence of new onset or worsening of EPGA during omalizumab treatment ${ }^{[113,114]}$. It should be noted that the majority of studies on omalizumab in EGPA patients are case reports and case series with a low level of evidence, and they focus on asthma and ENT disease, while no data are available on the benefit of the drug in vasculitis manifestation and severe EGPA that is considered to be limited ${ }^{[115]}$.

However, the real efficacy on vasculitis manifestations of anti-IL-5 medications is also debated because the MIRRA trial included asthma and sinonasal exacerbations as EGPA relapses, which is usually not recommended ${ }^{[116]}$.

With regard to vasculitis manifestations in EGPA patients, RTX seems to be highly effective, especially for ANCA-positive patients ${ }^{[17]}$, but data on asthma or ENT manifestations are still limited. One study reported a beneficiary effect of RTX on EGPA asthma, however the small size and the lack of a control group do not allow drawing final conclusions ${ }^{[118]}$.

\section{Surgical treatment}

The mainstay of treatment in AAV is medical, being surgical interventions delayed if possible given the potential risk of complications ${ }^{[119]}$. However, considering the ENT involvement, surgery may play a major role in at least four different settings: (1) diagnosis; (2) symptoms relief; (3) management of complications; and (4) reconstruction. Each of these surgical purposes finds its different weight and importance in relation to the underlying disease (GPA, EGPA, and MPA) and the different anatomical regions involved.

A recent systematic review on the role of surgery in AAV affecting the nose and sinuses demonstrated that most reports dealt with GPA in comparison with EGPA and MPA ${ }^{[73]}$. Although far from being considered surgical procedures, endoscopic nasal biopsies represent mini-invasive interventions frequently performed 
in the outpatient clinic and probably the easiest way to histologically confirm diagnosis in GPA and EGPA. Endoscopic sinus surgery should be indicated in GPA patients presenting with complications (e.g., mucoceles, fungal infections, and orbital/lacrimal pathways involvement). In cases unresponsive to medical treatments, endoscopic sinus surgery should be cautiously considered in GPA patients, since recent evidence suggests that sinus surgery is associated with osteitis progression and an increase in nasal space and crust formation ${ }^{[120]}$.

Reconstructive surgery in GPA (e.g., septal perforation or saddle nose repair) is controversial and needs careful planning. Although no consensus exists on the best time to perform it, it should be indicated when the disease is in complete remission, with Unadkat et al. ${ }^{[121]}$ suggesting waiting for further 6-12 months after disease stabilization.

Surgical measures for symptoms relief are reserved for refractory otologic manifestations in GPA. Patients with recurrent otitis media with persistent symptomatic middle ear effusions or eustachian tube dysfunction may benefit from myringotomy tube placement ${ }^{[122]}$. In the case of recurrent mastoiditis, mastoidectomy is advisable. An external approach and/or endonasal procedures may be used to perform dacryocystorhinostomy for epiphora and/or chronic infection in the lacrimal sac.

Although laryngo-tracheal manifestations of GPA are extremely rare (around 10\%-15\%), the subglottic stenosis is the most frequently observed. Failure of glucocorticoids and immunosuppressive treatment in symptoms relief is the main indication for surgical treatment of subglottic stenosis. Endoscopic intervention or dilation are preferred. Treatment failures are relatively high, ranging from $49 \%$ after one year to $80 \%$ at five years after the first procedure, according to a multicenter study including 47 patients ${ }^{[49]}$.

Considering EGPA patients, the role of endoscopic sinus surgery is still a matter of debate, with a controversial opinion reported in the literature ${ }^{[73]}$. In the future, surgery in EGPA will probably collide with the introduction of new monoclonal antibodies in the treatment regimens.

Surgical indications and proper timing of procedures is critical in AAV patients and should always be planned in a multidisciplinary setting in conjunction with all the medical figures involved to avoid poor outcomes and potential surgical complications.

\section{CONCLUSIONS}

ENT involvement in AAV, especially in GPA and EGPA, represents one of the most frequent symptoms. Although patients with ENT symptoms have better survival and less renal involvement, they typically experience persistent or relapsing disease together with long-term exposure to therapies, leading to irreversible damage.

The burden of sinonasal morbidity on quality of life is significant and comparable to other common chronic diseases, with an impairment especially of social functioning and well-being perception, perhaps as a result of the stigma of constant purulent rhinorrhea, embarrassing epistaxis, or nasal deformity from cartilage destruction ${ }^{[123,124]}$. The high impact of ENT symptoms on quality of life of AAV patients confirms the importance of their early treatment through specific local and systemic approaches ${ }^{[124]}$.

The otorhinolaryngologist is often one of the first physicians to see patients with GPA. The most frequent clinical manifestation of GPA is related to ENT involvement, in all of its forms, which may be the first or the only symptom. Thus, a close collaboration between the otorhinolaryngologist and rheumatologist is 
crucial for readily arriving at the proper diagnosis, which allows the timely initiation of appropriate therapy. Therefore, AAV patients must be followed up regularly and frequently, in order to detect early relapses and reduce damage accrual of the affected areas.

\section{DECLARATIONS}

\section{Authors' contributions}

Conceptualization: Padoan R, Campaniello D, Felicetti M, Cazzador D, Schiavon F

Investigation: Padoan R, Schiavon F

Writing review: Padoan R, Campaniello D, Felicetti M, Cazzador D, Schiavon F

Editing: Padoan R, Cazzador D, Schiavon F

Drafting and revising figures: Padoan $\mathrm{R}$, Cazzador D

Supervision of ENT surgery topics: Cazzador D, Schiavon F

\section{Availability of data and materials}

Not applicable.

\section{Financial support and sponsorship}

None.

\section{Conflicts of interest}

All authors declared that there are no conflicts of interest.

\section{Ethical approval and consent to participate}

Not applicable.

\section{Consent for publication}

Not applicable.

\section{Copyright}

(c) The Author(s) 2021.

\section{REFERENCES}

1. Lionaki S, Blyth ER, Hogan SL, et al. Classification of antineutrophil cytoplasmic autoantibody vasculitides: the role of antineutrophil cytoplasmic autoantibody specificity for myeloperoxidase or proteinase 3 in disease recognition and prognosis. Arthritis Rheum 2012;64:3452-62. DOI PubMed PMC

2. Fries JF, Hunder GG, Bloch DA, et al. The American College of Rheumatology 1990 criteria for the classification of vasculitis. Summary. Arthritis Rheum 1990;33:1135-6. DOI PubMed

3. Kallenberg CGM. Usefulness of antineutrophil cytoplasmic autoantibodies in diagnosing and managing systemic vasculitis. Curr Opin Rheumatol 2016;28:8-14. DOI PubMed

4. Lyons PA, Rayner TF, Trivedi S, et al. Genetically distinct subsets within ANCA-associated vasculitis. N Engl J Med 2012;367:21423. DOI PubMed PMC

5. Nishi R, Koike H, Ohyama K, et al. Differential clinicopathologic features of EGPA-associated neuropathy with and without ANCA. Neurology 2020;94:E1726-37. DOI PubMed

6. Holle JU, Gross WL, Holl-Ulrich K, et al. Prospective long-term follow-up of patients with localised Wegener's granulomatosis: Does it occur as persistent disease stage? Ann Rheum Dis 2010;69:1934-9. DOI PubMed

7. Felicetti M, Cazzador D, Padoan R, et al. Ear, nose and throat involvement in granulomatosis with polyangiitis: how it presents and how it determines disease severity and long-term outcomes. Clin Rheumatol 2018;37:1075-83. DOI PubMed

8. Mukhtyar C, Guillevin L, Cid MC, et al. EULAR recommendations for the management of primary small and medium vessel vasculitis. Ann Rheum Dis 2009;68:310-7. DOI PubMed

9. Yates M, Watts R. ANCA-associated vasculitis. Clin Med 2017;17:60-4. DOI PubMed PMC

10. Nishi R, Koike H, Ohyama K, et al. Association between IL-5 levels and the clinicopathologic features of eosinophilic granulomatosis with polyangiitis. Neurology 2021;96:226-9. DOI PubMed

11. Bligny D, Mahr A, Toumelin P Le, et al. Predicting mortality in systemic Wegener's granulomatosis: a survival analysis based on 93 patients. Arthritis Rheum 2004;51:83-91. DOI PubMed 
12. Rahmattulla C, De Lind van Wijngaarden RAF, Berden AE, et al. Renal function and ear, nose, throat involvement in anti-neutrophil cytoplasmic antibody-associated vasculitis: prospective data from the European Vasculitis Society clinical trials. Rheumatology (Oxford) 2015;54:899-907. DOI PubMed

13. Hogan SL, Falk RJ, Chin H, et al. Predictors of relapse and treatment resistance in antineutrophil cytoplasmic antibody-associated small-vessel vasculitis. Ann Intern Med 2005;143:621. DOI PubMed

14. Trimarchi M, Sinico RA, Teggi R, et al. Otorhinolaryngological manifestations in granulomatosis with polyangiitis (Wegener's). Autoimmun Rev 2013;12:501-5. DOI PubMed

15. Comarmond C, Pagnoux C, Khellaf M, et al. Eosinophilic granulomatosis with polyangiitis (Churg-Strauss): clinical characteristics and long-term followup of the 383 patients enrolled in the French Vasculitis Study Group cohort. Arthritis Rheum 2013;65:270-81. DOI PubMed

16. Durel C-A, Berthiller J, Caboni S, et al. Long-term followup of a multicenter cohort of 101 patients with eosinophilic granulomatosis with polyangiitis (Churg-Strauss). Arthritis Care Res (Hoboken) 2016;68:374-87. DOI PubMed

17. Millet A, Pederzoli-Ribeil M, Guillevin L, et al. Antineutrophil cytoplasmic antibody-associated vasculitides: is it time to split up the group? Ann Rheum Dis 2013;72:1273-9. DOI PubMed

18. Gubbels SP, Barkhuizen A, Hwang PH. Head and neck manifestations of wegener's granulomatosis. Otolaryngol Clin North Am 2003;36:685-705. DOI PubMed

19. Rasmussen N. Management of the ear, nose, and throat manifestations of Wegener granulomatosis: an otorhinolaryngologist's perspective. Curr Opin Rheumatol 2001;13:3-11. DOI PubMed

20. Kwan ASL, Rose GE. Lacrimal drainage surgery in Wegener's granulomatosis. Br J Ophthalmol 2000;84:329-31. DOI PubMed PMC

21. Kühn D, Hospowsky C, Both M, et al. Manifestation of granulomatosis with polyangiitis in head and neck. Clin Exp Rheumatol 2018;36 Supp1 111:78-84. PubMed

22. Holme SS, Moen JM, Kilian K, et al. Development of CT-based methods for longitudinal analyses of paranasal sinus osteitis in granulomatosis with polyangiitis. BMC Med Imaging 2019;19:13. DOI PubMed PMC

23. Muhle C, Reinhold-Keller E, Richter C, et al. MRI of the nasal cavity, the paranasal sinuses and orbits in Wegener's granulomatosis. Eur Radiol 1997;7:566-70. DOI PubMed

24. Wojciechowska J, Krajewski W, Krajewski P, et al. Granulomatosis With polyangiitis in otolaryngologist practice: a review of current knowledge. Clin Exp Otorhinolaryngol 2016;9:8-13. DOI PubMed PMC

25. Bacciu A, Bacciu S, Mercante G, et al. Ear, nose and throat manifestations of Churg-Strauss syndrome. Acta Otolaryngol 2006;126:503-9. DOI PubMed

26. Olsen KD, Neel HB, Deremee RA, et al. Nasal manifestations of allergic granulomatosis and angiitis (Churg-Strauss syndrome). Otolaryngol Head Neck Surg 1980;88:85-9. DOI PubMed

27. Suzuki M, Nakazono A, Morita S, et al. Comparison of clinical characteristics of the nasal manifestations of eosinophilic granulomatosis with polyangiitis (EGPA) and eosinophilic chronic rhinosinusitis (ECRS). Allergol Int 2021;70:143-4. DOI PubMed

28. Brescia G, Padoan R, Schiavon F, et al. Nasal polyps in eosinophilic granulomatosis with polyangiitis: structured histopathology and CD105 expression. Am J Otolaryngol Head Neck Med Surg 2020;41:102661. DOI PubMed

29. Contro G, Brescia G, Alessandrini L, et al. Neutrophil infiltrates and eosinophil aggregates in chronic rhinosinusitis with nasal polyps and EGPA. Clin Rheumatol;2021:40:1949-57. DOI PubMed

30. Brescia G, Schiavon F, Nicolè L, et al. No differences in nasal tissue inflammatory cells and adhesion molecules (iCAM-1 and vCAM-1) based on the comparison of EGPA with eosinophilic chronic sinusitis with polyposis. Am J Rhinol Allergy 2019;33:395402. DOI PubMed

31. Rahne T, Clauß F, Plontke SK, et al. Prevalence of hearing impairment in patients with rheumatoid arthritis, granulomatosis with polyangiitis (GPA, Wegener's granulomatosis), or systemic lupus erythematosus. Clin Rheumatol 2017;36:1501-10. DOI PubMed

32. Martinez Del Pero M, Walsh M, Luqmani R, et al. Long-term damage to the ENT system in Wegener's granulomatosis. Eur Arch Otorhinolaryngol 2011;268:733-9. DOI PubMed

33. Girasoli L, Cazzador D, Padoan R, et al. Update on vertigo in autoimmune disorders, from diagnosis to treatment. J Immunol Res 2018;2018:5072582. DOI PubMed PMC

34. Nogaki T, Keskin N, Azuma T, et al. Quantitative assessment of vestibular otopathology in granulomatosis with polyangitis: a temporal bone study. Laryngoscope Investig Otolaryngol 2018;3:473-7. DOI PubMed PMC

35. Ono N, Niiro H, Ueda A, et al. Characteristics of MPO-ANCA-positive granulomatosis with polyangiitis: a retrospective multi-center study in Japan. Rheumatol Int 2015;35:555-9. DOI PubMed

36. Schirmer JH, Wright MN, Herrmann K, et al. Myeloperoxidase-Antineutrophil Cytoplasmic Antibody (ANCA)-positive granulomatosis with polyangiitis (Wegener's) is a clinically distinct subset of ANCA-associated vasculitis: a retrospective analysis of 315 patients from a German vasculitis referral center. Arthritis Rheumatol 2016;68:2953-63. DOI PubMed

37. Ralli M, D’Aguanno V, Di Stadio A, et al. Audiovestibular symptoms in systemic autoimmune diseases. J Immunol Res 2018;2018:5798103. DOI PubMed PMC

38. Seccia V, Fortunato S, Cristofani-Mencacci L, et al. Focus on audiologic impairment in eosinophilic granulomatosis with polyangiitis. Laryngoscope 2016;126:2792-7. DOI PubMed

39. Nakamaru Y, Takagi D, Suzuki M, et al. Otologic and rhinologic manifestations of eosinophilic granulomatosis with polyangiitis. Audiol Neurotol 2016;21:45-53. DOI PubMed

40. Harabuchi Y, Kishibe K, Tateyama K, et al. Clinical characteristics, the diagnostic criteria and management recommendation of otitis 
media with antineutrophil cytoplasmic antibody (ANCA)-associated vasculitis (OMAAV) proposed by Japan Otological Society. Auris Nasus Larynx 2021;48:2-14. DOI PubMed

41. Harabuchi Y, Kishibe K, Tateyama K, et al. Clinical features and treatment outcomes of otitis media with antineutrophil cytoplasmic antibody (ANCA)-associated vasculitis (OMAAV): a retrospective analysis of 235 patients from a nationwide survey in Japan. Mod Rheumatol 2017;27:87-94. DOI PubMed

42. Girard C, Charles P, Terrier B, et al. Tracheobronchial stenoses in granulomatosis with polyangiitis (Wegener's): a report on 26 cases. Medicine (Baltimore) 2015;94:e1088. DOI PubMed PMC

43. Fijolek J, Wiatr E, Gawryluk D, et al. Intratracheal dilation-injection technique in the treatment of granulomatosis with polyangiitis patients with subglottic stenosis. J Rheumatol 2016;43:2042-8. DOI PubMed

44. Seccia V, Cristofani-Mencacci L, Dallan I, et al. Eosinophilic granulomatosis with polyangiitis and laryngeal involvement: Review of the literature and a cross-sectional prospective experience. J Laryngol Otol 2018;132:619-23. DOI PubMed

45. Del Pero MM, Jayne D, Chaudhry A, et al. Long-term outcome of airway stenosis in granulomatosis with polyangiitis (Wegener Granulomatosis): An observational study. JAMA Otolaryngol Head Neck Surg 2014;140:1038-44. DOI PubMed

46. Jordan NP, Verma H, Siddiqui A, et al. Morbidity and mortality associated with subglottic laryngotracheal stenosis in granulomatosis with polyangiitis (Wegener's granulomatosis): a single-centre experience in the United Kingdom. J Laryngol Otol 2014;128:831-7. DOI PubMed

47. Quinn KA, Gelbard A, Sibley C, et al. Subglottic stenosis and endobronchial disease in granulomatosis with polyangiitis. Rheumatology (Oxford) 2019;58:2203-11. DOI PubMed PMC

48. Guardiani E, Moghaddas HS, Lesser J, et al. Multilevel airway stenosis in patients with granulomatosis with polyangiitis (Wegener's). Am J Otolaryngol Head Neck Med Surg 2015;36:361-3. DOI PubMed

49. Terrier B, Dechartres A, Girard C, et al. Granulomatosis with polyangiitis: Endoscopic management of tracheobronchial stenosis: Results from a multicentre experience. Rheumatology (Oxford) 2015;54:1852-7. DOI PubMed

50. Alam DS, Rahul S, Raj S, et al. Upper airway manifestations of granulomatosis with polyangiitis. Cleve Clin J Med 2012;79:16-21. DOI PubMed

51. Zycinska K, Wardyn K, Zielonka TM, et al. Subglottic and tracheal stenosis due to Wegener's granulomatosis. Adv Exp Med Biol 2013;755:221-4. DOI PubMed

52. Church AC, Goldsmith K, Sivasothy P. Aspiration and development of subglottic stenosis in patients with Wegeners granulomatosis. J Laryngol Otol 2010;124:393-6. DOI PubMed

53. Gluth MB, Shinners PA, Kasperbauer JL. Subglottic stenosis associated with Wegener's granulomatosis. Laryngoscope 2003;113:1304-7. DOI PubMed

54. Marroquín-Fabián E, Ruiz N, Mena-Zúñiga J, et al. Frequency, treatment, evolution, and factors associated with the presence of tracheobronchial stenoses in granulomatosis with polyangiitis. Retrospective analysis of a case series from a single respiratory referral center. Semin Arthritis Rheum 2019;48:714-9. DOI PubMed

55. Sharma A, Deshmukh S, Dabholkar J. ENT manifestations of Wegeners granulomatosis. Otolaryngol Pol 2013;67:257-60. DOI PubMed

56. Langford CA, Sneller MC, Hallahan CW, et al. Clinical features and therapeutic management of subglottic stenosis in patients with Wegener's granulomatosis. Arthritis Rheum 1996;39:1754-60. DOI PubMed

57. Martinez Del Pero M, Rasmussen N, Chaudhry A, et al. Structured clinical assessment of the ear, nose and throat in patients with granulomatosis with polyangiitis (Wegener's). Eur Arch Otorhinolaryngol 2013;270:345-54. DOI PubMed

58. Taylor SC, Clayburgh DR, Rosenbaum JT, Schindler JS. Clinical manifestations and treatment of idiopathic and Wegener granulomatosis-associated subglottic stenosis. JAMA Otolaryngol Head Neck Surg 2013;139:76-81. DOI PubMed

59. Nico MMS, Pinto NT, Lourenço SV. From strawberry gingivitis to palatal perforation: The clinicopathological spectrum of oral mucosal lesions in granulomatosis with polyangiitis. J Oral Pathol Med 2020;49:443-9. DOI PubMed

60. Xing X, Zhang T, Wang X. Pediatric Wegener's granulomatosis with oral ulcers and progressive periodontitis: a case report. Oral Surg Oral Med Oral Pathol Oral Radiol Endod 2011:112. DOI PubMed

61. Knight JM, Hayduk MJ, Summerlin DJ, et al. "Strawberry" gingival hyperplasia: a pathognomonic mucocutaneous finding in Wegener granulomatosis. Arch Dermatol 2000;136:171-3. DOI PubMed

62. Eufinger H, Machtens E, Akuamoa-Boateng E. Oral manifestations of Wegener's granulomatosis. Review of the literature and report of a case. Int J Oral Maxillofac Surg 1992;21:50-3. DOI PubMed

63. Hernández G, Serrano C, Porras L, et al. Strawberry-like gingival tumor as the first clinical sign of Wegener's granulomatosis. $J$ Periodontol 2008;79:1297-303. DOI PubMed

64. Hanisch M, Fröhlich LF, Kleinheinz J. Gingival hyperplasia as first sign of recurrence of granulomatosis with polyangiitis (Wegener's granulomatosis): case report and review of the literature. BMC Oral Health 2016;17:33. DOI PubMed PMC

65. Trimarchi M, Bondi S, Della Torre E, Terreni MR, Bussi M. Palate perforation differentiates cocaine-induced midline destructive lesions from granulomatosis with polyangiitis. Acta Otorhinolaryngol Ital 2017;37:281-5. DOI PubMed PMC

66. Nelson RE, Hildrew DM, Deblieux T, et al. Wegener's Granulomatosis presenting as a parapharyngeal mass. J Louisiana State Med Soc Off organ Louisiana State Med Soc 2016;168:60-2. PubMed

67. Lee PY, Adil EA, Irace AL, et al. The presentation and management of granulomatosis with polyangiitis (Wegener's Granulomatosis) in the pediatric airway. Laryngoscope 2017;127:233-40. DOI PubMed

68. Shenavandeh S, Petramfar P. Three atypical manifestations of granulomatosis with polyangiitis: lateral medullary syndrome, anterior cheek mass and melting scleritis of eye. Reumatologia 2017;55:145-50. DOI PubMed PMC 
69. Masuda T, Izumi Y, Takeshita H, et al. Granulomatosis with polyangiitis presenting as a choroidal tumor. Case Rep Rheumatol 2015;2015:271823. DOI PubMed PMC

70. Spanuchart I, Zungsontiporn N, O-charoen P, et al. Granulomatosis with polyangiitis: a case of nasal mass, necrotic lung, and normal kidneys. Hawaii J Med Public Health 2015;74:27-9. PubMed PMC

71. Coates ML, Martinez Del Pero M. Updates in antineutrophil cytoplasmic antibody (ANCA)-associated vasculitis for the ENT surgeon. Clin Otolaryngol 2020;45:316-26. DOI PubMed

72. Greco A, Marinelli C, Fusconi M, et al. Clinic manifestations in granulomatosis with polyangiitis. Int J Immunopathol Pharmacol 2016;29:151-9. DOI PubMed PMC

73. Pendolino AL, Unadkat S, Zhang H, et al. The role of surgery in antineutrophil cytoplasmic antibody-associated vasculitides affecting the nose and sinuses: a systematic review. SAGE Open Med 2020;8:205031212093673. DOI PubMed PMC

74. Devaney KO, Travis WD, Hoffman G, et al. Interpretation of head and neck biopsies in Wegener's granulomatosis. a pathologic study of 126 biopsies in 70 patients. Am J Surg Pathol 1990;14:555-64. DOI PubMed

75. Seccia V, Baldini C, Latorre M, et al. Focus on the involvement of the nose and paranasal sinuses in Eosinophilic Granulomatosis with polyangiitis (Churg-Strauss Syndrome): nasal cytology reveals infiltration of eosinophils as a very common feature. Int Arch Allergy Immunol 2018;175:61-9. DOI PubMed

76. Vega Villanueva KL, Espinoza LR. Eosinophilic vasculitis. Curr Rheumatol Rep 2020;22:5. DOI PubMed

77. D’Anza B, Langford CA, Sindwani R. Sinonasal imaging findings in Granulomatosis with polyangiitis (Wegener granulomatosis): a systematic review. Am J Rhinol Allergy 2017;31:16-21. DOI PubMed

78. Pagnoux C. Updates in ANCA-associated vasculitis. Eur J Rheumatol 2016;3:122-33. DOI PubMed PMC

79. Carnevale C, Arancibia-Tagle D, Sarría-Echegaray P, et al. Head and neck manifestations of granulomatosis with polyangiitis: a retrospective analysis of 19 patients and review of the literature. Int Arch Otorhinolaryngol 2019;23:165-71. DOI PubMed PMC

80. Hernández-Rodríguez J, Hoffman GS, Koening CL. Surgical interventions and local therapy for Wegener's granulomatosis. Curr Opin Rheumatol 2010;22:29-36. DOI PubMed

81. Erickson VR, Hwang PH. Wegener's granulomatosis: current trends in diagnosis and management. Curr Opin Otolaryngol Head Neck Surg 2007;15:170-6. DOI PubMed

82. Yates M, Watts RA, Bajema IM, et al. EULAR/ERA-EDTA recommendations for the management of ANCA-associated vasculitis. Ann Rheum Dis 2016;75:1583-94. DOI PubMed

83. De Groot K, Rasmussen N, Bacon PA, et al. Randomized trial of cyclophosphamide versus methotrexate for induction of remission in early systemic antineutrophil cytoplasmic antibody-associated vasculitis. Arthritis Rheum 2005;52:2461-9. DOI PubMed

84. Puéchal X. Granulomatosis with polyangiitis (Wegener's). Joint Bone Spine 2020;87:572-8. DOI PubMed

85. Stegeman CA, Cohen Tervaert JW, De Jong PE, et al. Trimethoprim-sulfamethoxazole (Co-Trimoxazole) for the prevention of relapses of Wegener's granulomatosis. N Engl J Med 1996;335:16-20. DOI PubMed

86. Padoan R, Felicetti M, Gatto M, et al. Rituximab-associated hypogammaglobulinaemia in ANCA-associated vasculitis and connective tissue diseases: a longitudinal observational study. Clin Exp Rheumatol 2020;38:188-94. PubMed

87. Raffray L, Guillevin L. Rituximab treatment of ANCA-associated vasculitis. Expert Opin Biol Ther 2020;20:899-910. DOI PubMed

88. Okada M, Suemori K, Takagi D, et al. The treatment outcomes of rituximab for intractable otitis media with ANCA-associated vasculitis. Auris Nasus Larynx 2019;46:38-42. DOI PubMed

89. Durel C-A, Hot A, Trefond L, et al. Orbital mass in ANCA-associated vasculitides: data on clinical, biological, radiological and histological presentation, therapeutic management, and outcome from 59 patients. Rheumatology (Oxford) 2019;58:1565-73. DOI PubMed

90. Holle JU, Dubrau C, Herlyn K, et al. Rituximab for refractory granulomatosis with polyangiitis (Wegener's granulomatosis): comparison of efficacy in granulomatous versus vasculitic manifestations. Ann Rheum Dis 2012;71:327-33. DOI PubMed

91. Aries PM, Hellmich B, Voswinkel J, et al. Lack of efficacy of rituximab in Wegener's granulomatosis with refractory granulomatous manifestations. Ann Rheum Dis 2006;65:853-8. DOI PubMed PMC

92. Seo P, Specks U, Keogh KA. Efficacy of rituximab in limited Wegener's granulomatosis with refractory granulomatous manifestations. J Rheumatol 2008;35:2017-23. PubMed

93. Pullerits R, Ljevak M, Vikgren J, et al. Off-trial evaluation of the B cell-targeting treatment in the refractory cases of Antineutrophil Cytoplasmic Antibodies (ANCA)-associated vasculitis: long-term follow-up from a single centre. Scand J Immunol 2012;76:411-20. DOI PubMed

94. Wechsler ME, Akuthota P, Jayne D, et al. Mepolizumab or placebo for eosinophilic granulomatosis with polyangiitis. $N$ Engl J Med 2017;376:1921-32. DOI PubMed PMC

95. Ribi C, Cohen P, Pagnoux C, et al. Treatment of Churg-Strauss syndrome without poor-prognosis factors: a multicenter, prospective, randomized, open-label study of seventy-two patients. Arthritis Rheum 2008;58:586-94. DOI PubMed

96. Pagnoux C, Groh M. Optimal therapy and prospects for new medicines in eosinophilic granulomatosis with polyangiitis (ChurgStrauss syndrome). Expert Rev Clin Immunol 2016;12:1059-67. DOI PubMed

97. Cohen P, Pagnoux C, Mahr A, et al. Churg-Strauss syndrome with poor-prognosis factors: a prospective multicenter trial comparing glucocorticoids and six or twelve cyclophosphamide pulses in forty-eight patients. Arthritis Care Res 2007;57:686-93. DOI PubMed

98. Nagase H, Ueki S, Fujieda S. The roles of IL-5 and anti-IL-5 treatment in eosinophilic diseases: asthma, eosinophilic granulomatosis with polyangiitis, and eosinophilic chronic rhinosinusitis. Allergol Int 2020;69:178-86. DOI PubMed

99. Canzian A, Venhoff N, Urban ML, et al. Use of biologics to treat relapsing and/or refractory eosinophilic granulomatosis with polyangiitis: data from a European collaborative study. Arthritis Rheumatol 2020;73:498-503. DOI PubMed 
100. Manka LA, Guntur VP, Denson JL, et al. Efficacy and safety of reslizumab in the treatment of Eosinophilic Granulomatosis with Polyangiitis (EGPA). Ann Allergy Asthma Immunol 2021:S1081-1206(21)00097. DOI PubMed

101. Guntur VP, Manka LA, Denson JL, et al. Benralizumab as a steroid-sparing treatment option in eosinophilic granulomatosis with polyangiitis. J Allergy Clin Immunol Pract 2021;9:1186-93. DOI PubMed

102. Padoan R, Chieco Bianchi F, Marchi MR, et al. Benralizumab as a glucocorticoid-sparing treatment option for severe asthma in eosinophilic granulomatosis with polyangiitis. J Allergy Clin Immunol Pract 2020;8:3225-7.e2. DOI PubMed

103. Kita H. Eosinophils: Multifaceted biological properties and roles in health and disease. Immunol Rev 2011;242:161-77. DOI PubMed PMC

104. Laviolette M, Gossage DL, Gauvreau G, et al. Effects of benralizumab on airway eosinophils in asthmatic patients with sputum eosinophilia. J Allergy Clin Immunol 2013;132:1086-96. DOI PubMed PMC

105. Bourdin A, Husereau D, Molinari N, et al. Matching-adjusted indirect comparison of benralizumab versus interleukin-5 inhibitors for the treatment of severe asthma: a systematic review. Eur Respir J 2018;52:1801393. DOI PubMed PMC

106. Hanania NA, Alpan O, Hamilos DL, et al. Omalizumab in severe allergic asthma inadequately controlled with standard therapy: a randomized trial. Ann Intern Med 2011;154:573-82. DOI PubMed

107. Gevaert P, Omachi TA, Corren J, et al. Efficacy and safety of omalizumab in nasal polyposis: 2 randomized phase 3 trials. $J$ Allergy Clin Immunol 2020;146:595-605. DOI PubMed

108. Goldstein S, Gabriel S, Kianifard F, et al. Clinical features of adolescents with chronic idiopathic or spontaneous urticaria: review of omalizumab clinical trials. Ann Allergy Asthma Immunol 2017;118:500-4. DOI PubMed

109. Caruso C, Gencarelli G, Gaeta F, et al. Efficacy of omalizumab treatment in a man with occupational asthma and eosinophilic granulomatosis with polyangioitis. Ann Allergy Asthma Immunol 2018;120:209-11. DOI PubMed

110. Aguirre-Valencia D, Posso-Osorio I, Bravo JC, et al. Sequential rituximab and omalizumab for the treatment of eosinophilic granulomatosis with polyangiitis (Churg-Strauss syndrome). Clin Rheumatol 2017;36:2159-62. DOI PubMed

111. Detoraki A, Di Capua L, Varricchi G, et al. Omalizumab in patients with eosinophilic granulomatosis with polyangiitis: a 36-month follow-up study. J Asthma 2016;53:201-6. DOI PubMed

112. Jachiet M, Samson M, Cottin V, et al. Anti-IgE monoclonal antibody (Omalizumab) in refractory and relapsing eosinophilic granulomatosis with polyangiitis (Churg-Strauss): data on seventeen patients. Arthritis Rheumatol 2016;68:2274-82. DOI PubMed

113. Winchester DE, Jacob A, Murphy T. Omalizumab for Asthma. N Engl J Med 2006;355:1281-2. DOI PubMed

114. Puéchal X, Rivereau P, Vinchon F. Churg-Strauss syndrome associated with omalizumab. Eur J Intern Med 2008;19:364-6. DOI PubMed

115. Basta F, Mazzuca C, Nucera E, et al. Omalizumab in eosinophilic granulomatosis with polyangiitis: friend or foe? Clin Exp Rheumatol 2020;38 Suppl 124:214-20. PubMed

116. Groh M, Pagnoux C, Baldini C, et al. Eosinophilic granulomatosis with polyangiitis (Churg-Strauss) (EGPA) Consensus Task Force recommendations for evaluation and management. Eur J Intern Med 2015;26:545-53. DOI PubMed

117. Akiyama M, Kaneko Y, Takeuchi T. Rituximab for the treatment of eosinophilic granulomatosis with polyangiitis: a systematic literature review. Autoimmun Rev 2021;20:102737. DOI PubMed

118. Casal Moura M, Berti A, Keogh KA, et al. Asthma control in eosinophilic granulomatosis with polyangiitis treated with rituximab. Clin Rheumatol 2020;39:1581-90. DOI PubMed

119. Sattui SE, Lally L. Localized Granulomatous with polyangiitis (GPA): varied clinical presentations and update on treatment. Curr Allergy Asthma Rep 2020;20:56. DOI PubMed

120. Holme SS, Moen JM, Kilian K, et al. Impact of paranasal sinus surgery in granulomatosis with polyangiitis: a longitudinal computed tomography study. Laryngoscope 2020;130:E460-8. DOI PubMed

121. Unadkat SN, Pendolino AL, Kwame I, et al. Nasal reconstructive surgery for vasculitis affecting the nose: our two-centre international experience. Eur Arch Otorhinolaryngol 2020;277:3059-66. DOI PubMed

122. Sahyouni R, Moshtaghi O, Abouzari M, et al. A case series of granulomatosis with polyangiitis primarily diagnosed by otological manifestations. Ann Otol Rhinol Laryngol 2019;128:263-6. DOI PubMed

123. Srouji IA, Andrews P, Edwards C, et al. General and rhinosinusitis-related quality of life in patients with Wegener's granulomatosis. Laryngoscope 2006;116:1621-5. DOI PubMed

124. Cazzador D, Padoan R, Colangeli R, et al. Health-related quality of life in patients with anca-associated vasculitis and sinonasal involvement: a single-center cross-sectional study. J Clin Rheumatol 2020. DOI PubMed 